\title{
Adaptation to illness in relation to pain perceived by patients after surgery
}

\author{
Mariusz Chabowski ${ }^{1,2}$ \\ Michał Junke' \\ Jan Juzwiszyn' \\ Magdalena Milan' \\ Maciej Malinowski ${ }^{1,2}$ \\ Dariusz Janczak ${ }^{1,2}$ \\ 'Division of Surgical Specialties, \\ Department of Clinical Nursing, \\ Faculty of Health Science, Wroclaw \\ Medical University, ${ }^{2}$ Department \\ of Surgery, 4th Military Teaching \\ Hospital, Wroclaw, Poland
}

This article was published in the following Dove Press journal:

Journal of Pain Research

23 June 2017

Number of times this article has been viewed

Background: Pain is one of the factors that decrease quality of life. Undergoing surgery is inevitably associated with the sensation of pain, which can affect a patient's level of acceptance of an illness. The aim of the study was to evaluate the level of acceptance of illness in patients undergoing surgical treatment with relation to the pain perceived by them during surgical treatment and to determine other factors that affect adaptation to illness among patients subjected to invasive treatment.

Material and methods: The study was conducted on a group of 100 patients with mean age of 51.27 ( $\mathrm{SD}=18.98$ ) hospitalized in surgery departments in the Provincial Specialist Hospital in Wrocław, Poland, in April 2016. The Acceptance of Illness Scale (AIS) and the Visual Analog Scale (VAS) for pain were used.

Results: The mean score of VAS was 3.86 ( $\mathrm{SD}=2.02$ ). The mean score of AIS was 24.42 ( $\mathrm{SD}=7.35)$. The level of acceptance of illness was significantly negatively correlated with the intensity of pain $(p<0.001 ; r=-0.498)$, the number of coexisting diseases $(p=0.002 ; r=-0.31)$, age $(p<0.001 ; r=-0.391)$, and the period of time since the operation $(p=0.007 ; r=-0.266)$. Patients taking analgesics showed a significantly lower acceptance of illness than those who did not $(p=0.009)$. A patient's place of living, education, and sex had no significant impact on their acceptance of illness.

Conclusion: A higher level of pain translates into a lower adaptation to illness despite the use of analgesics, which may indicate that inadequate pain control leads to a decrease in the acceptance of illness. Further research on monitoring postoperative pain, as well as the development of postoperative prevention programs, is required.

Keywords: pain, acceptance of illness, surgical treatment, postoperative pain

\section{Introduction}

Advances in medicine, especially in surgical treatment, have allowed the reduction of morbidity and mortality associated with many diseases; however, the mortality rates for patients undergoing surgery differ between countries, which suggest the need to develop strategies aimed to improve care for this group of patients. ${ }^{1}$ Apart from the biological aspect, current understanding of invasive treatment should also include the social and mental domains, ${ }^{2}$ as it may happen that these aspects strongly affect the course of recovery of a patient subjected to invasive treatment as well. Mental and social factors can influence the attitude of a patient to the process of recovery and to determine compliance, which in turn can accelerate a return to full health. The ability to accept certain limitations of an illness helps a patient to adapt to that illness.

Correspondence: Mariusz Chabowski Department of Surgery, 4th Military Teaching Hospital, 5 Weigla Street, 50-98I Wroclaw, Poland

$\mathrm{Tel}+48261660247$

Fax +48 26I 660245

Email mariusz.chabowski@gmail.com 
Adaptation is a heterogeneous concept and depends on many factors. ${ }^{3}$ In the case of surgical treatment, it is associated with the level of pain perceived by a patient during treatment and convalescence. ${ }^{4,5}$

The possibility of adapting to a disease translates into acceptance of the disease, which is an important part of participation in the treatment process, compliance, and coping with the disease. A higher level of acceptance ensures better adaptation and a smaller sense of discomfort due to the illness. McCracken et al claim that positive change in the quality of life may be impossible without a patient's prior acceptance of certain issues connected with the disease as they stand. ${ }^{6}$ The paradox includes a resignation from the struggle to reach unattainable goals, which patients find hard to accept. But on the other hand, adaptation is not equal to resignation. Adaptation to illness is the recognition of one's real health condition and helps patients to cope with a disease, including the feeling of pain.

Surgery is, generally, considered a method of treatment strongly associated with feeling pain and the necessity of analgesia. The most widely used definition of pain was developed by the International Association for the Study of Pain (IASP). According to IASP, pain is "an unpleasant sensory and emotional experience associated with actual or potential tissue damage, or described in terms of such damage." ${ }^{\prime 7}$ This definition draws attention to the fact that pain is a subjective feeling which may be caused not only by tissue damage but which can be rooted in emotions as well, even in the course of surgical treatment. Pain also depends on many other factors, for example, as shown by Mancini et al, who discovered the association between pain perception and visual stimuli. ${ }^{8}$ The intensity of perceived pain cannot be unified, thus, pain is one of the factors that may affect the acceptance of illness.

\section{Aim of the study}

The aim of the study was to evaluate the level of acceptance of illness in patients undergoing surgical treatment with relation to the pain they perceived during surgical treatment and to determine other factors that affect patients' adaptation to illness.

\section{Materials and methods}

The study was conducted on a group of 100 patients hospitalized in surgery departments in the Provincial Specialist Hospital in Wrocław, Poland, in April 2016. Participation in the study was voluntary and anonymous, and the respondents were all adults. All the respondents gave written informed consent to participate in the study and answer the questionnaires. The study was approved by the Commission of Bioethics at Wroclaw Medical University.

For the majority of patients, the examination was performed on the second or third day after they had undergone surgery (41\%), but the number of days ranged from 0 to 24 . We used the Acceptance of Illness Scale (AIS) developed by Felton et al and adapted to Polish conditions by Jurczyński, which consists of 8 statements, each measured on the 5-point Likert scale. The total score ranges from 0 to 32, with higher scores indicating a higher level of acceptance. ${ }^{9}, 10$ The AIS addressed the cognitive-behavioral aspect of acceptance of illness and focuses on patients' feelings and their subjective assessment of how they are coping with a disease. It has good psychometric properties: internal reliability with Cronbach's alpha of 0.82 and a test-retest reliability coefficient of 0.69 over a period of 7 months.

Intensity of pain was measured using the Visual Analog Scale (VAS) for pain, which is currently one of the most common tools among scales used for pain assessment. In addition, it is widely used with postsurgical patients. It is a single-item scale and consists of a 10-cm horizontal line with the two end points labeled "no pain" and "worst pain ever", respectively. Patients were asked to draw a point on the scale which corresponded to the severity of the pain they felt. The answers were scored from 0 to 10 with a higher score indicating greater intensity of pain. The advantage of the VAS is its simplicity, which allows for quick and intuitive answers from the patients. ${ }^{11,12}$

The data were statistically analyzed using Statistica software v.10 (StatSoft, Tulsa, OK, USA). The Shapiro-Wilk test was used to analyze the distribution of the data. Pearson's coefficient was used to analyze correlations between variables of normal distribution, whereas Spearman's rank correlation coefficient was used between variables of distribution other than normal. For comparisons among groups, Student's $t$-test, Kruskal-Wallis test, and analysis of variance were used depending on the number of groups and the type of variable distribution. The data were considered to be statistically significant at a value of $p<0.05$.

\section{Results}

All patients completed the questionnaires. The mean age of respondents was $51.27(\mathrm{SD}=18.98)$ years and ranged between 18 and 93. Patients' sex, place of living, education, comorbidities, need for analgesics, and type of surgery are summarized in Table 1. The majority of respondents lived in the city, one-third had higher education, and the most common comorbidity was arterial hypertension. The number 
Table I Patients' characteristics and the overall level of acceptance of illness in the study group

\begin{tabular}{|c|c|}
\hline Variables & $\mathbf{N}(\%)$ \\
\hline \multicolumn{2}{|l|}{ Sex } \\
\hline Men & $43(43)$ \\
\hline Women & $57(57)$ \\
\hline \multicolumn{2}{|l|}{ Place of living } \\
\hline Village & $32(32)$ \\
\hline City & $68(68)$ \\
\hline \multicolumn{2}{|l|}{ Education } \\
\hline Primary & $17(17)$ \\
\hline Vocational & $27(27)$ \\
\hline Secondary & $20(20)$ \\
\hline Postsecondary & $3(3)$ \\
\hline University & $33(33)$ \\
\hline \multicolumn{2}{|l|}{ Marital status } \\
\hline Single & $26(26)$ \\
\hline Married & $44(44)$ \\
\hline Widow/widower & $17(17)$ \\
\hline Divorced & $13(13)$ \\
\hline \multicolumn{2}{|l|}{ Type or cause of surgery } \\
\hline Vascular surgery & $6(6)$ \\
\hline Appendectomy & $8(8)$ \\
\hline Hernia & $7(7)$ \\
\hline Cesarean section & $2(2)$ \\
\hline Cholecystectomy & $8(8)$ \\
\hline Peptic ulcer disease & $3(3)$ \\
\hline Surgery of the spine & $2(2)$ \\
\hline Aneurysm & $3(3)$ \\
\hline Removal of foreign body from the wound & $2(2)$ \\
\hline Dermatological surgery & $5(5)$ \\
\hline Gynecological surgery & $2(2)$ \\
\hline Cardiac surgery & $3(3)$ \\
\hline Kidney surgery & $6(6)$ \\
\hline Ophthalmic surgery & $5(5)$ \\
\hline Oncological treatment & $7(7)$ \\
\hline Orthopedic surgery & $9(9)$ \\
\hline Urological surgery & $5(5)$ \\
\hline Fracture & $9(9)$ \\
\hline Miscellaneous & $8(8)$ \\
\hline \multicolumn{2}{|l|}{ Comorbidities } \\
\hline Hypertension & $2 I(2 I)$ \\
\hline Asthma & $5(5)$ \\
\hline Diabetes & $11(11)$ \\
\hline Peptic ulcer disease & $3(3)$ \\
\hline Heart failure & $7(7)$ \\
\hline Hypercholesterolemia & $4(4)$ \\
\hline Renal insufficiency & $2(2)$ \\
\hline Osteoporosis & $5(5)$ \\
\hline Atherosclerosis & $2(2)$ \\
\hline Degenerative changes of the spine & $3(3)$ \\
\hline Obesity & $3(3)$ \\
\hline Miscellaneous & $27(27)$ \\
\hline \multicolumn{2}{|l|}{ Taking analgesics } \\
\hline Yes & $86(86)$ \\
\hline No & $14(14)$ \\
\hline \multicolumn{2}{|l|}{ Overall level of acceptance of illness } \\
\hline Lack of acceptance & $23(23)$ \\
\hline Moderate acceptance level & $54(54)$ \\
\hline High acceptance level & $23(23)$ \\
\hline
\end{tabular}

Table 2 Visual Analog Scale (VAS) for pain - distribution of answers

\begin{tabular}{lllllllllll}
\hline \multicolumn{2}{l}{ VAS for pain } \\
\hline No pain & 1 & 2 & 3 & 4 & 5 & 6 & 7 & 8 & 9 & The worst pain ever \\
1 & 8 & 19 & 17 & 20 & 14 & 8 & 4 & 4 & 3 & 2 \\
\hline
\end{tabular}

of coexisting diseases ranged from none (36\%) to $4(4 \%)$. The reason for surgical treatment varied; thus, the extent of surgery and patients' condition varied as well. Surgery was associated with pain in $99 \%$ of cases, as only one of the patients declared no pain. The mean score of VAS was 3.86 $(\mathrm{SD}=2.02)$. Most of the respondents reported low to medium levels of pain, whereas in $13 \%$ of them, the intensity of pain was 7 or higher (Table 2). Over half of the respondents had a medium level of acceptance of illness. The mean score of AIS was $24.42(\mathrm{SD}=7.35)$. The distribution of answers for each item on the AIS is presented in Table 3.

The level of acceptance of illness was significantly negatively correlated with the intensity of pain $(p<0.001$; $r=-0.498)$, the number of coexisting diseases $(p=0.002$; $r=-0.31)$, age $(p<0.001 ; r=-0.391)$, and length of time since the operation ( $p=0.007 ; r=-0.266$ ). These associations indicated that greater pain, worse health condition as measured by the number of comorbidities, and older age decreased a patient's acceptance of illness. In addition, patients taking analgesics showed a significantly lower acceptance of illness than those who did not ( $p=0.009$; mean score 23.65 vs 29.14 , respectively). A patient's place of living, education, and sex had no significant impact on their acceptance of illness ( $p=0.716, p=0.220$, and $p=0.263$, respectively). Analysis of marital status revealed that a significant difference was found only between single and widowed patients $(p<0.001)$. Group of patients who had undergone different types of surgery showed differences in terms of the level of acceptance of illness. Less severe operations were associated with a higher acceptance of illness; however, statistical analysis has less impact due to the small size of the groups.

\section{Discussion}

The level of acceptance of illness depends on many factors. In our study, the mean score of acceptance of illness measured among patients hospitalized on surgery wards was 24.42 . We found that factors such as greater pain, more comorbidities, older age, taking analgesics, and a longer time since the operation were correlated with a lower level of acceptance of illness.

The overall level of acceptance of illness differs among patients with various diseases. Uchmanowicz et al reported 
Table 3 Acceptance of illness scale (AIS) - distribution of answers for each item

\begin{tabular}{|c|c|c|c|c|c|}
\hline AIS items & $\begin{array}{l}\text { Strongly } \\
\text { agree }\end{array}$ & Agree & Undecided & Disagree & $\begin{array}{l}\text { Strongly } \\
\text { disagree }\end{array}$ \\
\hline I have problems with adjusting to the limitations imposed by the disease & 27 & 26 & 30 & 12 & 5 \\
\hline Due to my health condition, I am not able to do what I like the most & 33 & 30 & 16 & 15 & 6 \\
\hline The disease makes me feel unwanted & 8 & 22 & 20 & 20 & 30 \\
\hline Health problems make me more dependent on others than I would like to be & 20 & 36 & 19 & 17 & 8 \\
\hline The disease makes me a burden for my family and friends & 10 & 30 & 20 & 17 & 23 \\
\hline Due to my health condition, I do not feel a really valuable man & 13 & 11 & 21 & 21 & 34 \\
\hline I will never be as self-sufficient to the extent to which I would like to be & 16 & 15 & 15 & 19 & 35 \\
\hline I believe people that stay with me are often embarrassed because of my disease & 5 & 17 & 20 & 26 & 32 \\
\hline
\end{tabular}

a mean value of $20.6 \pm 7.62$ scores in patients with chronic obstructive pulmonary disease, ${ }^{13}$ Nowicki et al reported $25.5 \pm 7.6$ scores in patients with breast cancer in the early postoperative period, ${ }^{14}$ while Religioni et al reported 28.46 in breast cancer patients, 23.17 in lung cancer patients, 27.74 in patients with colon and rectum cancers, and 30.39 in patients with prostate cancer. ${ }^{15}$ The findings from our study show a relatively low acceptance of illness when compared with patients with cancer, but higher when compared with patients with severe pulmonary disorders. Studies from the literature address mostly the topic of acceptance of illness in terms of a given disease. The novel approach of this study is that the acceptance of illness is analyzed among patients treated with a similar invasive method resulting in acute, short-term pain, which should be properly managed by introducing preoperative, intraoperative, and postoperative strategies. ${ }^{16,17}$ Relatively low acceptance of illness in patients undergoing surgery may relate to the necessity of having invasive treatment which affects their health condition and results in short-term disability. Surgical patients, in contrast to other chronically ill patients, have no time for adaptation to symptoms related to invasive treatment. In addition, the age range of patients from our study is quite wide, which may indicate that older patients have more problems with adaptation to their health condition during postoperative period.

Surgery is associated with pain which is rather acute than chronic in nature. The feeling of pain should decrease during the period of convalescence and should last no longer than 6 months. Postoperative pain is considered to be transient; however, its intensity and duration may be affected by many factors, so the decrease in the intensity of pain is not constant during convalescence. In our study, over half of our respondents reported moderately intense pain, but cases of severe and maximal pain also occurred. The level of pain in our study group is lower, but the percentage of patients suffering from pain is higher than in other studies. Other researchers report that acute postoperative pain occurs in $>80 \%$ of patients vs $99 \%$ in our study, but $75 \%$ of these patients report moderate or higher levels in the severity of pain. ${ }^{16}$ An alarming fact is that Gan et al reported that after discharge, 74\% of surgical patients were experiencing levels of pain intensity similar to the immediate postsurgical period. ${ }^{18}$ In our study, we only addressed the sensations of pain perceived after the operation but before leaving the hospital, although the impact of pain on acceptance of illness is also noticeable in the early postoperative period.

Another factor directly associated with the intensity of postoperative pain is pain management. Data from the literature show that only $23 \%$ of surgical nurses monitor the intensity of pain during the postoperative period. In addition, many patients receive analgesics on demand, but only minimal doses, particularly in the case of stronger drugs such as opioids, because nurses are afraid of the side effects of such drugs, including addiction and respiratory depression. ${ }^{19,20}$ Another barrier to proper pain management indicated by nurses is unsatisfactory access to evidence-based knowledge in the approach to pain management and a lack of support from physicians. ${ }^{21-23}$ Our study showed that a lower level of illness acceptance was associated with greater pain and taking analgesics, which may be due to inadequate pain control. In addition, the level of acceptance of illness decreased over time, which may be explained by the negative impact of pain on functional recovery and quality of life as well as the possible development of persistent postsurgical pain. Data from the literature suggest that acute postoperative pain may become chronic. The percentage of such cases depends on the extent of the surgical intervention and tissue damage, and varies from $10 \%$ for a cesarian section up to $50 \%$ for coronary artery bypass surgery. ${ }^{24}$

Czerw et al reported that the period of time since the diagnosis of cancer did not influence the level of acceptance of illness. ${ }^{25}$ Also, Karademas et al found that acceptance of illness remained stable in cardiac patients during a 6-month 
period. ${ }^{26}$ Interestingly, in our study, acceptance of illness decreased over time among our surgical patients. One of the reasons for this decrease in adaptation may be associated with the discrepancy between patients' expectations related to their return to health after radical invasive treatment and their current health condition. It should also be mentioned that $99 \%$ of our patients reported sensations of pain. Also, our study was conducted among hospitalized patients, as those patients who completed the questionnaires later after surgery had had to stay longer in the hospital; thus, return to health took longer as well. Studies from the literature emphasize the importance of preoperative education and information about changes in the body, symptoms, and feelings that patients can experience after an operation. ${ }^{27,28}$ Such education is conducted before surgery, and sometimes there may be a lack of time or doctor-patient contact to meet patients' needs related to information about all aspects of the surgical treatment.

Our study showed that lower acceptance of illness was associated with worse health condition with reference to the number of coexisting diseases and older age. Studies from the literature do not confirm any association between age and acceptance of illness; ${ }^{14,25}$ however, Uchmanowicz et al reported an insignificantly lower acceptance of illness in older patients who had additional burdens. ${ }^{13}$ The significant negative impact of age on illness acceptance shown by our study draws attention to the fact that elderly people are worse candidates for surgical treatment than younger ones, not only in terms of worse general health condition, longer convalescence, and longer wound healing process, ${ }^{29}$ but also in terms of metal attitude to such treatment as confirmed here by their lower level of acceptance of illness.

\section{Conclusion}

In acute postoperative pain, a higher level of pain translates into lower adaptation to illness despite the use of analgesics, which may indicate inadequate pain control leading to a decrease in acceptance of illness. Further research on monitoring postoperative pain, as well as the development of postoperative prevention programs, is required.

\section{Disclosure}

The authors report no conflicts of interest in this work.

\section{References}

1. Pearse RM, Moreno RP, Bauer P, et al. Mortality after surgery in Europe: a 7 day cohort study. Lancet. 2012;380(9847):1059-1065.

2. WrightJG. Outcomes research: what to measure. WorldJSurg. 1999;23(12): 1224-1226.
3. Molassiotis A. A conceptual model of adaptation to illness and quality of life for cancer patients treated with bone marrow transplants. $J A d v$ Nurs. 1997;26(3):572-579.

4. Dance C, DeBerard MS, Gundy CJ. Pain acceptance potentially mediates the relationship between pain catastrophizing and post-surgery outcomes among compensated lumbar fusion patients. J Pain Res. 2017;10: $65-72$.

5. Bono CM, Harris MB, Warholic N, et al. Pain intensity and patients' acceptance of surgical complication risks with lumbar fusion. Spine (Phila Pa 1976). 2013;38(2):140-147.

6. McCracken LM, Carson JW, Eccleston C, Keefe FJ. Acceptance and change in the context of chronic pain. Pain. 2004;109(1-2):4-7.

7. International Association for the Study of Pain. IASP Taxonomy; 1994. Available from:http://www.iasp-pain.org/Taxonomy\#Pain. Accessed November 15, 2016.

8. Mancini F, Longo MR, Kammers MP, Haggard P. Visual distortion of body size modulates pain perception. Psychol Sci. 2011;22(3): $325-330$.

9. Jurczyński Z. [Measurement tools in the promotion and psychoobcology of health]. Warszawa: Pracownia Testów Psychologicznych; 2009. Polish.

10. Felton BJ, Revenson TA, Hinrichsen GA. Stress and coping in the explanation of psychological adjustment among chronically ill adults. Soc Sci Med. 1984;18(10):889-898.

11. Katz J, Melzack R. Measurement of pain. Surg Clin North Am. 1999;79(2):231-252.

12. Hawker GA, Mian S, Kendzerska T, French M. Measures of adult pain: visual analog scale for pain (VAS pain), numeric rating scale for pain (NRS pain), McGill pain questionnaire (MPQ), short-form McGill pain questionnaire (SF-MPQ), chronic pain grade scale (CPGS), short form-36 bodily pain scale (SF-36 BPS), and measure of intermittent and constant osteoarthritis pain (ICOAP). Arthritis Care Res (Hoboken). 2011;63(Suppl 11):S240-S252.

13. Uchmanowicz I, Jankowska-Polanska B, Motowidlo U, Uchmanowicz B, Chabowski M. Assessment of illness acceptance by patients with COPD and the prevalence of depression and anxiety in COPD. Int $J$ Chron Obstruct Pulmon Dis. 2016;11:963-970.

14. Nowicki A, Krzemkowska E, Rhone P. Acceptance of illness after surgery in patients with breast cancer in the early postoperative period. Pol Przegl Chir. 2015;87(11):539-550.

15. Religioni U, Czerw A, Deptala A. Acceptance of cancer in patients diagnosed with lung, breast, colorectal and prostate carcinoma. Iran J Public Health. 2015;44(8):1135-1142.

16. Chou R, Gordon DB, de Leon-Casasola OA, et al. Management of postoperative pain: a clinical practice guideline from the American Pain Society, the American Society of Regional Anesthesia and Pain Medicine, and the American Society of Anesthesiologists' Committee on Regional Anesthesia, Executive Committee, and Administrative Council. J Pain. 2016;17(2):131-157.

17. Gordon DB, de Leon-Casasola OA, Wu CL, Sluka KA, Brennan TJ, Chou R. Research gaps in practice guidelines for acute postoperative pain management in adults: findings from a review of the evidence for an American Pain Society Clinical Practice Guideline. J Pain. 2016;17(2): $158-166$.

18. Gan TJ, Habib AS, Miller TE, White W, Apfelbaum JL. Incidence, patient satisfaction, and perceptions of post-surgical pain: results from a US national survey. Curr Med Res Opin. 2014;30(1):149-160.

19. Apfelbaum JL, Chen C, Mehta SS, Gan TJ. Postoperative pain experience: results from a national survey suggest postoperative pain continues to be undermanaged. Anesth Analg. 2003;97(2):534-540.

20. Knap M, Szyrmer B, Kowalczyk-Sroka B. [The level of knowledge about the management of postoperative pain among nurses from surgical wards]. Problemy pielegniarstwa. 2010;18(2):129-133. Polish.

21. Medrzycka-Dabrowska W, Dabrowski S, Gutysz-Wojnicka A, Basinski A. Polish nurses' perceived barriers in using evidence-based practice in pain management. Int Nurs Rev. 2016;63(3):316-327. 
22. Yin HH, Tse MM, Wong FK. Systematic review of the predisposing, enabling, and reinforcing factors which influence nursing administration of opioids in the postoperative period. Jpn J Nurs Sci. 2015;12(4): 259-275.

23. Leegaard M, Watt-Watson J, McGillion M, Costello J, Elgie-Watson J, Partridge K. Nurses' educational needs for pain management of post-cardiac surgery patients: a qualitative study. J Cardiovasc Nurs. 2011;26(4):312-320.

24. Kehlet H, Jensen TS, Woolf CJ. Persistent postsurgical pain: risk factors and prevention. Lancet. 2006;367(9522):1618-1625.

25. Czerw AI, Bilinska M, Deptala A. The assessment of the impact of socio-economic factors in accepting cancer using the Acceptance of Illness Scale (AIS). Contemp Oncol (Pozn). 2016;20(3):261-265.
26. Karademas EC, Tsagaraki A, Lambrou N. Illness acceptance, hospitalization stress and subjective health in a sample of chronic patients admitted to hospital. J Health Psychol. 2009;14(8):1243-1250.

27. McCleane GJ, Cooper R. The nature of pre-operative anxiety. Anaesthesia. 1990;45(2):153-155.

28. Pawlak A, Krejca M, Janas-Kozik M, Krupka-Matuszczyk I, Rajewska J, Bochenek A. Ocena lęku i depresji w okresie okołooperacyjnym u pacjentów poddawanych rewaskularyzacji mięśnia sercowego [Evaluation of anxiety and depression in the perioperative period in patients subjected to myocardial revascularization]. Psychatr Pol. 2012;46(1):63-74. Polish.

29. Engeland CG, Bosch JA, Cacioppo JT, Marucha PT. Mucosal wound healing: the roles of age and sex. Arch Surg. 2006;141(12):1193-1197.
Journal of Pain Research

\section{Publish your work in this journal}

The Journal of Pain Research is an international, peer reviewed, open access, online journal that welcomes laboratory and clinical findings in the fields of pain research and the prevention and management of pain. Original research, reviews, symposium reports, hypothesis formation and commentaries are all considered for publication.

\section{Dovepress}

The manuscript management system is completely online and includes a very quick and fair peer-review system, which is all easy to use. Visit http://www.dovepress.com/testimonials.php to read real quotes from published authors. 